\title{
Cutaneous myiasis in an elderly debilitated patient
}

\author{
S. Roche ${ }^{1}$, S. Cross' ${ }^{1}$ I. Burgess ${ }^{2}$, C. Pines ${ }^{1}$ and A.C.D. Cayley ${ }^{1}$ \\ ${ }^{1}$ Department of Medicine for the Elderly, Central Middlesex Hospital, Acton Lane, London NW10 and \\ ${ }^{2}$ Medical Entomology Centre, University of Cambridge, Cambridge, UK.
}

\begin{abstract}
Summary: A 77 year old woman, with chronic immobility, developed bed sores which became infested with maggots. This progressed to cutaneous myiasis which is an uncommon complication of this particular phenomenon.
\end{abstract}

\section{Introduction}

Myiasis is the feeding of dipteran fly larvae (maggots) on the living tissue of vertebrate animals, including humans. ${ }^{1}$ We report a case of cutaneous myiasis caused by Lucilia sericata. As far as we are aware, this is the first reported case in Great Britain caused by this species.

\section{Case report}

A 77 year old woman was admitted to the Central Middlesex in May 1989 with an acute left hemiparesis. She had previously been fit and self-caring and smoked and drank alcohol occasionally. Her drugs on admission included quinine sulphate and hypromellose eye drops.

On examination, she was drowsy and had an obvious dysarthria. Her cardiovascular, respiratory and abdominal systems were unremarkable. In her central nervous system she had a left central seventh nerve palsy with a left hemiparesis grade $3 / 5$. Her left plantar response was upgoing.

Laboratory investigations included a full blood count, biochemical screen, serum protein, liver function, and thyroid function, which were all normal. Her electrocardiogram and chest X-ray were within normal limits. Over the following fortnight she was totally dependent on nursing care and needed treatment with intravenous fluids. Ten weeks after admission a sacral sore was noted which grew anaerobes on culture. She was treated with metronidazole, Sorbsan dressings and oral zinc. Despite this she soon developed sores on both hips. She was put on a Pegasus bed and changed from Sorbsan to Varidase dressings. After 2 weeks her sores showed a marked improvement with the right hip only now needing dressings.

Correspondence: S. Roche, M.R.C.P., Department of Medicine for the Elderly, St Charles Hospital, Exmoor Street, London W10, UK.

Accepted: 4 April 1990
Three weeks later, the nurses noticed a mass of maggots while changing the patient's dressing. They were lying on the skin surface adjacent to, but not within, the right hip sore, medial aspect of the right buttock and just outside the vulva. It was also noted that her other sores, which had previously healed, had deteriorated. A sample of maggots was sent to the Medical Entomology Centre at the University of Cambridge for identification.

\section{Methorlology}

The larvae were third instar maggots in the post feeding stage of development and were obviously migrating from the tissues in search of a pupation site. The gut was gorged with blood and tissue. Identification of genus was made from the characteristic appearance of the posterior spiracles; three straight, outwardly angled slits and a single thickening of the rim between the lateral pair of each side: and a single non-pigmented oral sclerite in the cephalopharyngeal skeleton. ${ }^{2}$

Of the four species with morphologically similar maggots: Lucilia sericata, L. caesar, L. illustris and $L$. richardaii, only $L$. sericata is likely to be found in an urban environment entering a building. Regrettably it was not possible to rear any adults to confirm this identification.

Unfortunately, the patient developed a chest infection and, despite treatment with antibiotics, died on 12th October 1989. A post mortem examination was carried out. No maggots were found and there were no fistulae between her abdominal and pelvic cavities.

\section{Discussion}

Myiasis is classified as obligatory when the fly maggot is so adapted to parasitism that it can only survive on living animals. Facultative myiasis ${ }^{1,3}$ 
occurs when maggots that would normally live on cadavers or other inert materials are able opportunistically to gain access via wounds to living tissues which they would otherwise be unable to penetrate. Cutaneous myiasis in man is most common in the tropics. In temperate regions it is usually found in individuals with poor hygiene and open wounds. There are a variety of clinical forms depending on the species of fly involved. ${ }^{4}$ In temperate regions the most important causes of myiasis are members of the Family Calliphoridae (Cyclorrhapha), the blow flies, which in the United States are responsible for $86-90 \%$ of cases. ${ }^{5}$

Lucilia sericata, the common greenbottle, is a cosmopolitan fly which probably originated in the northern hemisphere. Its body is metallic green with a blue, yellow or coppery sheen, measuring up to $10 \mathrm{~mm}$ in length and is morphologically indistinguishable from several related species other than by microscopic observation of the numbers and distribution of bristles on the thorax. ${ }^{6} \mathrm{~L}$. sericata may be particularly attracted to the smell of urine ${ }^{1,6}$ and it is interesting to note that our patient had a catheter which leaked urine at the time of infestation. This may have, along with the very hot weather, increased her predisposition to attack by this species. In a recent prospective study from Brisbane, ${ }^{7}$ the related species $L$. cuprina was highly implicated in their cases of cutaneous myiasis. Both species are facultative parasites and usually breed in carrion or

\section{References}

1. Patton, W.S. Notes on myiasis producing diptera of man and animals. Bull Entomol Res 1921, 12: 239-261.

2. Oldroyd, H. \& Smith, K.G.V. Eggs and larvae of flies. In: Smith, K.G.V. (ed.) Insects and Other Arthropods of Medical Importance. British Museum (Natural History), London, 1973, pp. 289-323.

3. Morris, K.R. Myiasis in humans. Med J Aust 1989, 150: 233-237.

4. Alexander, J.O. Cutaneous myiasis. In: Alexander, J.O. (ed.) Arthropods and Human Skin. Springer-Verlag, New York, 1984, pp. 87-113.

5. Schreiber, M.M., Schuckmell, N. \& Sampsel, J. Human myiasis. JAMA 1964, 188: 828-829. decomposing matter. The Brisbane study was the first to show L. cuprina affecting humans in Australia despite it being a widespread pest of sheep throughout the country. Consequently, it is possible that $L$. sericata is more commonly a myiasis agent in humans than recent literature suggests.

It is the most likely of the Calliphoridae to enter buildings through sunny windows and is more inclined to lay its eggs indoors. Consequently it presents the greatest risk for the immobile patient with a wound. The risk is enhanced if the body or extremities are at all hypothermic. Cutaneous myiasis, unlike some other forms, is not itself life threatening. However, physicians should be alert to the possibility of accidental pathogenesis by native flies or infestation by non-indigenous flies now that air travel has made distant places easily accessible.

Therapy usually consists of medical or surgical debridement or application of locally active toxic substances. Chloroform ${ }^{8}$ and ether ${ }^{9}$ are the most used topical toxic agent to complement mechanical debridement. Repeated daily treatment may be necessary for several days.

\section{Acknowledgements}

We wish to thank Mrs W. Munday for typing the manuscript and Miss Wilson, Acting Chief Pharmacist.
6. Busvine, J.R. Blowflies (Calliphoridae). In: Busvine, J.R. (ed.) Insects and Hygiene. Chapman and Hall, London, 1980, pp. 219-226.

7. Lukin, L.G. Human cutaneous myiasis in Brisbane: A prospective study. Med J Aust 1989, 150: 237-240.

8. Domonkos, A.N., Arnold, H.L. Jr. \& Ordom, R.B. In Andrew's Diseases of the Skin: Clinical Dermatology. W.B. Saunders, Philadelphia, 1982, pp. 558-560.

9. Mocias, E.G., Graham, A.J., Green, M. et al. Cutaneous myiasis in south Texas. $N$ Engl J Med 1973, 283: 1239-1241. 